\title{
Nasal Colonization of Methicillin-Resistant Staphylococcus aureus in Patients' Attendants in a Tertiary Care Hospital of Pakistan
}

\author{
Taaha Muddassir Mirza ${ }^{1}$, Rimsha Ali ${ }^{1}$, Huma Musarrat Khan ${ }^{2}$ \\ ${ }^{1}$ House Officer, Medicine Unit I, Benazir Bhutto Hospital, Rawalpindi, Pakistan \\ ${ }^{2}$ Professor, Head, Department of Anatomy, Foundation University Medical College, Islamabad, Pakistan
}

\begin{abstract}
Background: Hospital associated Methicillin-resistant Staphylococcus aureus (MRSA) is a serious health concern, as its infection is associated with high rates of mortality and morbidity. Health care professionals around the globe are concerned by the increased prevalence of these bacteria in the hospital environment. With this background in mind, this study was conducted to determine the frequency of nasal colonization of methicillin-resistant staphylococcus in attendants of admitted patients in a tertiary care hospital in Pakistan.

Material and Methods: A cross-sectional study was conducted in Holy Family Hospital, Rawalpindi, Pakistan from $10^{\text {th }}$ May to $31^{\text {st }}$ August, 2016. Attendants of sixty admitted patients were selected by simple random sampling. Two nasal swabs samples were obtained from these attendants; the first at the beginning of the study with a hospital stay of less than 12 hours, and the second when their stay in the hospital had exceeded 48 hours. The samples were cultured on Cystine lactose electrolyte deficient agar, Mannitol Salt Agar, and Nutrient Agar. The colonies were subjected to Gram staining, catalase test, coagulase test, and methicillin/oxacillin sensitivity using the Kirby-Bauer's disc diffusion method. Frequencies and percentages were calculated. Chi-Square test was applied and statistical significance calculated for the demographic data.

Results: The first culture report (at $<12$ hours hospital stay) showed that $46 / 60$ (76.7\%) attendants were not found to have any resistant strain of Staphylococcus. These 46 attendants were then subjected to a second culture (after 48 hours hospital stay), which showed that 24/46 (52.2\%) were now colonized with methicillin-resistant Staphylococcus species (MRSA; $n=7$ and MR other than $S$. aureus; $n=17$ ). There was no statistically significant difference between colonization of isolates and relationship to gender, age, residence, and co-morbid conditions.

Conclusions: The frequency of colonization with resistant strains of Staphylococcus aureus in attendants of admitted patients increased after being exposed to the hospital environment for more than forty-eight hours.

Key words: Attendants, Colonization, Infection, MRSA, Staphylococcus aureus
\end{abstract}

Authors' Contribution:

manuscript design and drafting; Critical

analysis and manuscript review; Data

analysis; Manuscript Editing.

Cite this article. Mirza TM, Ali R, Khan HM. Nasal Colonization of Methicillin-Resistant Staphylococcus aureus in Patients' Attendants in a Tertiary Care Hospital of Pakistan. J Islamabad Med Dental Coll.2020; 9(2): 115-122. Doi: 10.35787/jimdc.v9i2.512

\section{Article info:}

Huma Musarrat Khan

Email: huma.anat@gmail.com
Received: March 5, 2020

Accepted: June 18, 2020
Funding Source: Nil Conflict of Interest: Nil 


\section{Introduction}

Staphylococcus aureus (S. aureus) is a bacterium, that colonizes the anterior nares of $20-80 \%$ of the human population. ${ }^{1-3}$ Healthy individuals who are carriers of the organism have an increased risk of contracting an infection. ${ }^{4} \mathrm{~A}$ resistant form of $\mathrm{S}$. aureus called, Methicillin-resistant Staphylococcus aureus (MRSA) has also been isolated. It is a grampositive bacterium characterized by the presence of PBP-2a, a penicillin-binding protein encoded by mecA gene, which makes it resistant to beta-lactam antimicrobials. $^{5}$ This resistant form was first isolated in a British study in 1960, and since then it has gone through speedy evolutionary changes and epidemiologic expansion. ${ }^{6}$

On the basis of acquisition and genetics, two common varieties of this bacterium have emerged; community-associated MRSA (CA-MRSA) and the hospital-associated MRSA (HA-MRSA). ${ }^{7}$ In the United States, the first case of CA-MRSA infection was reported in 1980s. ${ }^{8}$ These infections commonly presented as skin and soft-tissue infections (SSTI) of variable severity in previously healthy individuals. ${ }^{9}$ Hospital-acquired MRSA rates increased rapidly after the 1990s. MRSA is a common cause of lifethreatening infections that requires aggressive management and consumption of resources. ${ }^{10}$ Risk factors for HA-MRSA infections include prolonged antibiotic use, extended hospital stay, MRSA colonization and exposure to MRSA infections.5 Studies report that community-associated MRSA (CA-MRSA) strains at times also spread into hospitals, causing life-threatening infections. This indicates that the genotypes of strains of Staphylococcus aureus causing HA-MRSA infections are becoming more diverse. ${ }^{11}$

The prevalence of MRSA infection varies in different parts of the world. Studies show that in South-east Asia, the incidence of MRSA ranges from $2.3 \%$ to $69.1 \%$ of $\mathrm{S}$. aureus infections, which is a great healthcare concern. The pooled colonization of MRSA has been estimated to $1.3 \%$ of general population ${ }^{12}$ and studies are showing an increase in this percentage. A study conducted in USA revealed that in females, the risk factors for colonization include 60 years of age or older, poor socioeconomic setup, and diabetes. Whereas in males, exposure to healthcare institutes has been considered as the only major risk factor. ${ }^{13}$

As colonization with MRSA significantly increases the risk of infection by this organism, it is essential to estimate the prevalence of its colonization in healthy individuals. ${ }^{13}$ In Pakistan, the attendants of the hospitalized patients are in close proximity of not only the patients, but also the doctors, healthcare staff and the hospital environment in general, and therefore at a risk of getting colonized or infected. ${ }^{14}$ Despite many studies outlining the prevalence of MRSA colonization in healthcare professionals and patients, little or no studies have been conducted on the attendants who are also exposed to this resistant bacterium. ${ }^{15}$

With this background in mind, the current study was conducted to determine the frequency of colonization of MRSA (HA-MRSA) in attendants of patients admitted to a tertiary care hospital in Pakistan.

\section{Material and Methods}

This cross-sectional study was conducted in Holy Family Hospital, Rawalpindi, Pakistan from $10^{\text {th }}$ May to $31^{\text {st }}$ August, 2016 after obtaining permission from the Institutional Research Forum. The study was conducted on attendants accompanying admitted patients. Total of 60 attendants were selected by simple random sampling. The sample included adult attendants of patients who had spent less than 12 hours in the hospital and whose total expected hospital stay would be more than 48 
hours. Exclusion criteria included attendants with a history of exposure to the hospital as a patient, patient's attendant, or healthcare worker in the past 6 months. Data was collected using a questionnaire.

Sampling was done in two stages. Initially, a nasal swab (for primary culture) was taken from the patient's attendants $(n=60)$ when their stay in the hospital had not exceeded 12 hours. The attendants whose primary culture report was negative for resistant Staphylococcus $(n=46)$ were enrolled for a second nasal swab. These swabs were taken for a second culture after they had spent more than 48 hours in the hospital.

After obtaining informed consent and basic demographic data of the attendants, samples were collected using sterile cotton swabs from both anterior nares of each of the participants. The samples were transported to the laboratory in sterile containers and processed immediately as the primary culture specimen. They were first cultured on CLED Agar (Cystine lactose electrolyte deficient agar) and were incubated at $37^{\circ} \mathrm{C}$ for 24 hours. Yellow-colored colonies obtained in the samples indicated likely presence of Staphylococcus aureus. These colonies were then transferred to Mannitol Salt Agar (MSA), a medium selective for the identification of Staphylococcus aureus. The plates were incubated for $37^{\circ} \mathrm{C}$ for 48 hours. The colonies that fermented mannitol appeared yellow or golden, indicating the presence of Staphylococcus aureus. These colonies were then selected from the MSA and were cultured on Nutrient Agar. The colonies subsequently obtained were subjected to Gram staining, Catalase test, and Coagulase test to differentiate $S$. aureus from other species of Staphylococcus. S aureus colonies were also tested for methicillin/oxacillin susceptibility. This was done using the Kirby-Bauer's disc diffusion method. $^{2,13}$ The dose of oxacillin used was 5 $\mu \mathrm{g} / \mathrm{disc}$. The plates were incubated at $37^{\circ} \mathrm{C}$ for 24 hours and zones of clearance were measured around the disc. If the zone of clearance was $<20 \mathrm{~mm}$, the organism was considered to be resistant to methicillin.

Subjects with a negative primary culture report for resistant bacteria (MRSA) were further investigated by taking a second swab. Specimens from these subjects were collected again from both anterior nares (secondary culture specimen) after their hospital stay exceeded 48 hours, and processed by the same methodology. The data was analyzed using SPSS version 24. Percentages and frequencies were calculated. Chi-square test was applied to calculate statistical significance between male and female attendants, different age groups, place of residence, and any existing co-morbid. A $P$-value of $<0.05$ was taken as significant.

\section{Results}

The total number of participants was 60 , out of which 25 (41.7\%) were males and 35 (58.3\%) were females. Approximately 34 (56.7\%) of the attendants resided in rural areas and the rest in urban localities. Out of the 60 attendants, 4 (6.67\%) were diabetic and 14 (6.67\%) were hypertensive. The rest $(42 ; 70 \%)$ had no diagnosed co-morbid diseases. None of the subjects were on antibiotic therapy.

The results of the first nasal swab culture report are given in Tables I and II. Of the 60 subjects, 44 (73.3\%) showed positive results for staphylococcus isolation, with the highest frequency for Methicillin-sensitive Staphylococcus species (30; 50\%) (Table I). Attendants with methicillin-resistant Staphylococci $(n=14)$ were dropped out of the study (Table I). The remaining 46 attendants were incorporated in the second stage of the study. The results of the second culture report are given in Table I and III. A total of 24/46 (52.1\%) attendants were positive for colonization with methicillinresistant strains of Staphylococcus (Table I). 


\begin{tabular}{|l|c|c|c|c|}
\hline \multicolumn{5}{|c|}{ Table I: Frequency distribution of isolates from nasal swab culture of patient's attendants } \\
\hline \multirow{2}{*}{ Isolates } & First Culture Report (n=60) & \multicolumn{2}{c|}{ Second Culture Report ( $\mathbf{n = 4 6 )}$} \\
\cline { 2 - 5 } & Frequency & Percentage & Frequency & Percentage \\
\hline Methicillin sensitive Staphylococcus species & 30 & 50 & 11 & 23.9 \\
\hline $\begin{array}{l}\text { Methicillin-resistant Staphylococcus species } \\
\text { other than S. aureus }\end{array}$ & 10 & 16.7 & 17 & 36.9 \\
\hline Methicillin resistant Staphylococcus aureus & 4 & 6.7 & 7 & 15.2 \\
\hline None & 16 & 26.7 & 11 & 23.9 \\
\hline
\end{tabular}

\begin{tabular}{|c|c|c|c|c|c|c|}
\hline \multicolumn{2}{|l|}{ Variables } & $\begin{array}{l}\text { MSSS } \\
(n=30)\end{array}$ & $\begin{array}{l}\text { MRSS other than } \\
\text { S. aureus } \\
(n=10)\end{array}$ & $\begin{array}{l}\text { MRSA } \\
(n=4)\end{array}$ & $\begin{array}{l}\text { None } \\
(n=16)\end{array}$ & $P$-value* \\
\hline \multirow{2}{*}{$\begin{array}{l}\text { Gender } \\
(n=60)\end{array}$} & $\begin{array}{l}\text { Male } \\
(n=25)\end{array}$ & $\begin{array}{c}12 \\
(40 \%)\end{array}$ & $\begin{array}{c}3 \\
(30 \%) \\
\end{array}$ & $\begin{array}{c}3 \\
(75 \%) \\
\end{array}$ & $\begin{array}{c}7 \\
(43.8 \%) \\
\end{array}$ & \multirow[b]{2}{*}{0.484} \\
\hline & $\begin{array}{l}\text { Female } \\
(n=35)\end{array}$ & $\begin{array}{c}18 \\
(60 \%)\end{array}$ & $\begin{array}{c}7 \\
(70 \%)\end{array}$ & $\begin{array}{c}1 \\
(25 \%)\end{array}$ & $\begin{array}{c}9 \\
(56.3 \%) \\
\end{array}$ & \\
\hline \multirow{3}{*}{$\begin{array}{l}\text { Age (years) } \\
(n=60)\end{array}$} & $\begin{array}{c}<30 \\
(n=23)\end{array}$ & $\begin{array}{c}12 \\
(40 \%) \\
\end{array}$ & $\begin{array}{c}4 \\
(40 \%) \\
\end{array}$ & $\begin{array}{c}2 \\
(50 \%) \\
\end{array}$ & $\begin{array}{c}5 \\
(31.3 \%) \\
\end{array}$ & \multirow{3}{*}{0.643} \\
\hline & $\begin{array}{l}30-55 \\
(n=29)\end{array}$ & $\begin{array}{c}16 \\
(53.3 \%)\end{array}$ & $\begin{array}{c}4 \\
(40 \%)\end{array}$ & $\begin{array}{c}2 \\
(50 \%)\end{array}$ & $\begin{array}{c}7 \\
(43.8 \%)\end{array}$ & \\
\hline & $\begin{array}{l}\geq 55 \\
(n=8)\end{array}$ & $\begin{array}{c}2 \\
(6.7 \%) \\
\end{array}$ & $\begin{array}{c}2 \\
(20 \%)\end{array}$ & $\begin{array}{c}0 \\
(0 \%)\end{array}$ & $\begin{array}{c}4 \\
(25 \%) \\
\end{array}$ & \\
\hline \multirow{2}{*}{$\begin{array}{l}\text { Residence } \\
(\mathrm{n}=60)\end{array}$} & $\begin{array}{c}\text { Urban Areas } \\
(n=26)\end{array}$ & $\begin{array}{c}14 \\
(46.7 \%) \\
\end{array}$ & $\begin{array}{c}3 \\
(30 \%) \\
\end{array}$ & $\begin{array}{c}2 \\
(20 \%) \\
\end{array}$ & $\begin{array}{c}7 \\
(43.8 \%) \\
\end{array}$ & \multirow{2}{*}{0.817} \\
\hline & $\begin{array}{l}\text { Rural Areas } \\
(n=34)\end{array}$ & $\begin{array}{c}16 \\
(53.3 \%)\end{array}$ & $\begin{array}{c}7 \\
(70 \%)\end{array}$ & $\begin{array}{c}2 \\
(20 \%)\end{array}$ & $\begin{array}{c}9 \\
(56.3 \%) \\
\end{array}$ & \\
\hline \multirow{3}{*}{$\begin{array}{l}\text { Co- } \\
\text { morbidity } \\
(n=60)\end{array}$} & $\begin{array}{l}\text { Hypertension } \\
(\mathrm{n}=14)\end{array}$ & $\begin{array}{c}7 \\
(23.3 \%) \\
\end{array}$ & $\begin{array}{c}1 \\
(10 \%)\end{array}$ & $\begin{array}{c}1 \\
(25 \%)\end{array}$ & $\begin{array}{c}5 \\
(31.3 \%) \\
\end{array}$ & \multirow{3}{*}{0.060} \\
\hline & $\begin{array}{l}\text { Diabetes } \\
(n=4)\end{array}$ & $\begin{array}{c}0 \\
(0 \%)\end{array}$ & $\begin{array}{c}3 \\
(30 \%)\end{array}$ & $\begin{array}{c}0 \\
(0 \%)\end{array}$ & $\begin{array}{c}1 \\
(6.3 \%)\end{array}$ & \\
\hline & $\begin{array}{l}\text { None } \\
(n=42)\end{array}$ & $\begin{array}{c}23 \\
(76.7 \%) \\
\end{array}$ & $\begin{array}{c}6 \\
(60 \%) \\
\end{array}$ & $\begin{array}{c}3 \\
(75 \%)\end{array}$ & $\begin{array}{c}10 \\
(62.5 \%)\end{array}$ & \\
\hline
\end{tabular}

${ }^{*} P<0.05$ was considered statistically significant MSSS-Methicillin sensitive staphylococcus species; MRSS-Methicillin-resistant staphylococcus species; MRSA-Methicillin resistant staphylococcus aureus

There was no significant statistical difference in the colonization of isolates related to gender, different age groups, place of residence, and any associated co-morbidity (Table II and III).

\section{Discussion}

Staphylococcus aureus colonizes the nares of a large proportion of the general population and poses a substantial threat as a serious pathogen. ${ }^{16}$
In the present study, colonization of staphylococcus in apparently healthy attendants in the primary culture report was $73.3 \%$ and $76.1 \%$ in the secondary culture report when the attendants had been exposed to the hospital environment for more than 48 hours which is similar to the percentages observed in other related studies. ${ }^{1}$

Resistance to antimicrobials is a global health concern, and drug resistance of Staph aureus is a serious threat. MRSA is generally associated with poor clinical outcomes. 


\begin{tabular}{|c|c|c|c|c|c|c|}
\hline \multicolumn{7}{|c|}{ Table III: Basic demographic data and frequency of isolates of second nasal swab culture } \\
\hline \multicolumn{2}{|c|}{ Variables } & \multirow{2}{*}{$\begin{array}{c}\begin{array}{c}\text { MSSS } \\
(n=11)\end{array} \\
\begin{array}{c}3 \\
(27.3 \%)\end{array}\end{array}$} & \multirow{2}{*}{$\begin{array}{c}\text { MRSS other } \\
\text { than S. aureus } \\
(\mathbf{n}=17)\end{array}$} & \multirow{2}{*}{$\begin{array}{c}\begin{array}{c}\text { MRSA } \\
(n=7)\end{array} \\
4 \\
(57.1 \%)\end{array}$} & \multirow{2}{*}{$\begin{array}{c}\begin{array}{c}\text { None } \\
(\mathbf{n}=11)\end{array} \\
5 \\
(45.5 \%)\end{array}$} & \multirow{3}{*}{$\begin{array}{c}P \text {-value* } \\
0.790\end{array}$} \\
\hline \multirow{2}{*}{$\begin{array}{l}\text { Gender } \\
(n=46)\end{array}$} & $\begin{array}{l}\text { Male } \\
(n=19)\end{array}$ & & & & & \\
\hline & $\begin{array}{l}\text { Female } \\
(n=27)\end{array}$ & $\begin{array}{c}8 \\
(72.7 \%)\end{array}$ & $\begin{array}{c}10 \\
(58.8 \%)\end{array}$ & $\begin{array}{c}3 \\
(42.9 \%)\end{array}$ & $\begin{array}{c}6 \\
(54.5 \%) \\
\end{array}$ & \\
\hline \multirow{3}{*}{$\begin{array}{l}\text { Age (years) } \\
(n=46)\end{array}$} & $\begin{array}{c}<30 \\
(n=17)\end{array}$ & $\begin{array}{c}5 \\
(45.5 \%) \\
\end{array}$ & $\begin{array}{c}7 \\
(41.2 \%) \\
\end{array}$ & $\begin{array}{c}2 \\
(28.6 \%) \\
\end{array}$ & $\begin{array}{c}3 \\
(27.3 \%) \\
\end{array}$ & \multirow{3}{*}{0.838} \\
\hline & $\begin{array}{l}30-55 \\
(n=23)\end{array}$ & $\begin{array}{c}6 \\
(54.5 \%)\end{array}$ & $\begin{array}{c}8 \\
(47.1 \%)\end{array}$ & $\begin{array}{c}4 \\
(57.1 \%) \\
\end{array}$ & $\begin{array}{c}5 \\
(45.5 \%)\end{array}$ & \\
\hline & $\begin{array}{c}\geq 55 \\
(n=6)\end{array}$ & $\begin{array}{c}0 \\
(0 \%)\end{array}$ & $\begin{array}{c}2 \\
(11.8 \%)\end{array}$ & $\begin{array}{c}1 \\
(14.3 \%)\end{array}$ & $\begin{array}{c}3 \\
(27.3 \%)\end{array}$ & \\
\hline \multirow{2}{*}{$\begin{array}{l}\text { Residence } \\
(n=46)\end{array}$} & $\begin{array}{l}\text { Urban Areas } \\
(n=21)\end{array}$ & $\begin{array}{c}3 \\
(27.3 \%)\end{array}$ & $\begin{array}{c}9 \\
(52.9 \%)\end{array}$ & $\begin{array}{c}4 \\
(57.1 \%)\end{array}$ & $\begin{array}{c}5 \\
(45.5 \%)\end{array}$ & \multirow{2}{*}{0.611} \\
\hline & $\begin{array}{c}\text { Rural Areas } \\
(n=25)\end{array}$ & $\begin{array}{c}8 \\
(72.7 \%) \\
\end{array}$ & $\begin{array}{c}8 \\
(47.1 \%) \\
\end{array}$ & $\begin{array}{c}3 \\
(42.9 \%) \\
\end{array}$ & $\begin{array}{c}6 \\
(54.5 \%) \\
\end{array}$ & \\
\hline \multirow{3}{*}{$\begin{array}{l}\text { Co- } \\
\text { morbidity } \\
(n=46)\end{array}$} & $\begin{array}{c}\text { Hypertension } \\
(n=12)\end{array}$ & $\begin{array}{c}2 \\
(18.2 \%)\end{array}$ & $\begin{array}{c}4 \\
(23.5 \%)\end{array}$ & $\begin{array}{c}3 \\
(42.9 \%)\end{array}$ & $\begin{array}{c}3 \\
(27.3 \%)\end{array}$ & \multirow{3}{*}{0.305} \\
\hline & $\begin{array}{l}\text { Diabetes } \\
(n=1)\end{array}$ & $\begin{array}{c}0 \\
(0 \%) \\
\end{array}$ & $\begin{array}{c}0 \\
(0 \%) \\
\end{array}$ & $\begin{array}{c}0 \\
(0 \%)\end{array}$ & $\begin{array}{c}1 \\
(9.1 \%) \\
\end{array}$ & \\
\hline & $\begin{array}{l}\text { None } \\
(n=33)\end{array}$ & $\begin{array}{c}9 \\
(81.8 \%)\end{array}$ & $\begin{array}{c}13 \\
(76.5 \%)\end{array}$ & $\begin{array}{c}4 \\
(57.1 \%)\end{array}$ & $\begin{array}{c}7 \\
(63.6 \%)\end{array}$ & \\
\hline
\end{tabular}

* $P<0.05$ was considered statistically significant MSSS-Methicillin sensitive staphylococcus species; MRSS-Methicillin-resistant staphylococcus species; MRSA-Methicillin resistant staphylococcus aureus

It causes metastatic infections such as septic arthritis, infective endocarditis, osteomyelitis, and septic shock leading to high rates of mortality and morbidity. ${ }^{17}$ The risk factors for MRSA infection include prolonged antibiotic use, extended hospital stays, MRSA colonization, and exposure to MRSA infection. There are two varieties of MRSA, the healthcare-associated MRSA and the communityassociated MRSA, both of which differ from each other in their clinical presentations and epidemiology. ${ }^{18}$ However, the line between the two is blurred with a considerable overlap occurring between the two. ${ }^{18}$ In the present study, 4/60 (6.7\%) subjects were harboring resistant Staphylococcus aureus on primary culture. This can be taken as CA-MRSA as these subjects had little or no exposure to a hospital set-up in the recent past. This percentage is lower than that reported by a study in a teaching hospital of Nepal, which claimed a percentage of $13.1 \%$ of nasal colonization rate of MRSA in patient's attendants. ${ }^{3}$ Forty-eight hours after exposure to the hospital environment, the percentage of attendants with MRSA increased to 7/46 (15.21\%), which can be considered as HAMRSA. Other studies show variable percentages of MRSA in attendants. An Indian study reported S. aureus colonization of $45.5 \%$ with MRSA carriage rate of $33.3 \%$ in attendant accompanying the patients. ${ }^{19}$ In contrast, another study claimed this percentage to be as low as $8.2 \%$, which is less than the present study. ${ }^{3}$ Recent studies have indicated that approximately $65 \%$ of all S. aureus isolated from ICUs are MRSA. ${ }^{12,13}$

Multiple studies have been done in Pakistan and the world to check the prevalence of MRSA in the hospital settings. These researches have focused on health care professionals, patients, and laboratory cultures. A multicentered research done by Hafiz and his colleagues indicated that MRSA was 
present in a wide range of 2 to $61 \%$ of the specimens collected by various laboratories in major cities of Pakistan, varying from city to city.15Another study conducted in Peshawar showed that $62.7 \%$ of healthcare workers were colonized with MRSA. ${ }^{20}$ This high percentage may be explained in light of the prolonged hospital exposure of health care providers in contrast to the brief 48 hours stay of attendants in the present study.

The more alarming statistics are related to the nasal colonization of the resistant species of Staphylococcus (MRSA) other than Staph aureus. The primary culture report showed that 14 out of 60 (23.3\%) attendants had resistant species of Staphylococcus. After exposure to the hospital environment, this percentage increased to $17 / 46$ (36.95\%). This large number presents a challenge, as this resistant bacterium may be transmitted to patients and healthcare providers, thus causing severe infections in the already compromised patients. ${ }^{21,22}$ In the present study no significant difference in age groups was observed in relation to colonization of Staph aureus. However, a study on prevalence of MRSA in Eritrea claimed a higher incidence of colonization of staph aureus in subjects less than 18 years of age. ${ }^{23}$

Unlike all the previous researches, the present study focuses on the attendants. In most of the general hospitals of Southeast Asia, the attendants give hands-on care and emotional support to the patient. ${ }^{14}$ This can act as a double-edged weapon; not only can attendants with MRSA colonization infect the patients, but as our study has shown, attendants can also acquire MRSA and harbor it. These attendants thus act as vectors and further facilitate the spread of bacteria within the hospital and the community.

It has been indicated by multiple studies that Methicillin-resistant Staphylococcus aureus (MRSA)is more virulent than Methicillin-sensitive $S$.
Aureus (MSSA) strains. ${ }^{12}$ However, other studies have shown that due to the heterogenic nature of the resistant population, quantitative laboratory analysis of the virulence factors show conflicting results with some researches stating that MSSA is more virulent. $^{24,25}$

In light of the present study, the need for regular screening is emphasized. It is proposed that the frequency of exposure of the attendants to the patients and the hospital environment should be decreased. All attendants intending to stay with the patient for longer than 48 hours should be screened on entry in the hospital and on their departure. Those positive for resistant species of Staphylococcus should not be allowed to stay in the hospital with their patient. All health care professionals should be made aware of the nosocomial transmission of bacteria and should be regularly screened. The doctors should take into account the nasal carriage rates of MRSA in their hospital while making therapeutic decisions.

The main limitation of the present study is a small sample size confined to a single tertiary care hospital. Moreover, due to limited number, the attendants were not categorized on the basis of wards (Medicine, Surgery, Gynae \& Obstetrics etc.), ICU and private rooms. Therefore, these findings cannot be generalized to all the patient's attendants in the hospital.

\section{Conclusion}

The frequency of colonization with resistant strains of Staphylococcus aureus in attendants of admitted patients increases after being exposed to the hospital environment for more than forty-eight hours.

\section{References}

1. Brown AF, Leech JM, Rogers TR, McLoughlin RM. Staphylococcus aureus colonization: Modulation of host immune response and impact on human 
vaccine design. Front Immunol. 2014; 4(JAN): 1-38. Doi: 10.3389/fimmu.2013.00507

2. Mehraj J, Witte W, Akmatov MK, Layer F, Werner G, Krause G. Epidemiology of Staphylococcus aureus Nasal Carriage Patterns in the Community. Curr Top Microbiol Immunol. 2016; 398: 55-87. Doi: 10.1007/82_2016_497

3. Shakya B, Shrestha S, Mitra T. Nasal carriage rate of methicillin resistant Staphylococcus aureus among at National Medical College Teaching Hospital, Birgunj, Nepal. Nepal Med Coll J. 2010; 12(May 2008): 26-9.

4. Stenehjem E, Rimland D. MRSA nasal colonization burden and risk of MRSA infection. Am J Infect Control. 2013; 41(5): 405-10. Doi: 10.1016/j. ajic.2012.07.017.

5. Choo EJ. Community-Associated MethicillinResistant Staphylococcus aureus in Nosocomial Infections. Infect Chemother. 2017; 49(2): 158. Doi: 10.3947/ic.2017.49.2.158

6. Deresinski S. Methicillin-resistant Staphylococcus aureus: an evolutionary, epidemiologic, and therapeutic odyssey. Clin Infect Dis. 2005; 40(4): 562-73. Doi: 10.1086/427701

7. Peng H, Liu D, Ma Y, Gao W. Comparison of community- and healthcare-associated methicillinresistant Staphylococcus aureus isolates at a Chinese tertiary hospital, 2012-2017. Sci Rep. 2018; 8(1): 17916. Doi: 10.1038/s41598-018-36206-5

8. Bukharie HA. A review of community-acquired methicillin-resistant Staphylococcus aureus for primary care physicians. J Family Community Med. 2010; 17(3): 117-20. Doi: 10.4103/1319-1683. 74320

9. Stryjewski ME, Chambers HF. Skin and Soft-Tissue Infections Caused by Community-Acquired Methicillin-Resistant Staphylococcus aureus. Clin Infect Dis. 2008; 46(S5): S368-77. Doi: 10.1086/ 533593

10. Okwu MU, Olley M, Akpoka AO, Izevbuwa OE. Methicillin-resistant Staphylococcus aureus (MRSA) and anti-MRSA activities of extracts of some medicinal plants: A brief review. AIMS Microbiol. 2019; 5(2): 117-37. Doi: 10.3934/microbiol. 2019.2.117.
11. Joo E-J, Chung DR, Kim SH, Baek JY, Lee NY, Cho SY, et al. Emergence of Community-Genotype Methicillin-Resistant Staphylococcus aureus in Korean Hospitals: Clinical Characteristics of Nosocomial Infections by Community-Genotype Strain. Infect Chemother. 2017; 49(2): 109. Doi: 10.3947/ic.2017.49.2.109.

12. Hassoun A, Linden PK, Friedman B. Incidence, prevalence, and management of MRSA bacteremia across patient populations - a review of recent developments in MRSA management and treatment. Crit Care. 2017; 21(1): 211. Doi: 10.1186/s13054-017-1801-3

13. Gorwitz RJ, Kruszon-Moran D, McAllister SK, McQuillan G, McDougal LK, Fosheim GE, et al. Changes in the Prevalence of Nasal Colonization with Staphylococcus aureus in the United States, 2001-2004. J Infect Dis. 2008; 197(9): 1226-34. Doi: $10.1086 / 533494$

14. Sultana R, Rimi NA, Islam MS, Nahar N, Luby SP, Gurley ES. Role of Patients' Attendants in Transmission and Prevention of Nosocomial Infections in Bangladeshi Public Hospitals. Int J Infect Dis. 2008; 12: e369. Doi: 10.1016/j. ijid.2008.05.979

15. Hafiz S, Hafiz AN, Ali L, Chughtai AS, Memon B, Ahmed $A$, et al. Methicillin resistant Staphylococcus aureus: a multicentre study. JPMA. 2002; 52: 312-5.

16. Haaber J, Penadés JR IH. Transfer of Antibiotic Resistance in Staphylococcus aureus. Format Abstr Trends Microbiol. 2017; 25(11): 893-905. Doi: 10.1016/j.tim.2017.05.011

17. van Hal SJ, Jensen SO, Vaska VL, Espedido BA, Paterson DL, Gosbell IB. Predictors of Mortality in Staphylococcus aureus Bacteremia. Clin Microbiol Rev. 2012; 25(2): 362-86. Doi: 10.1128/CMR.0502211

18. Salmenlinna S, Lyytikäinen O, Vuopio-Varkila J. Community acquired methicillin resistant Staphylococcus aureus, Finland. Emerg Infect Dis. 2002; 8(6): 602-7. Doi: 10.3201/eid0806.010313

19. Khan F, Shukla I, Rizvi M, Sultan A, Kumar P. Screening for Detection of MRSA in Patients and Hospital Staff of a Tertiary Institutional Hospital. Int J Curr Microbiol App Sci. 2013; 2(12): 569-74. 
20. Asghar M, Asghar N, Mumtaz S, Khan SA, Ullah I, Munir $\mathrm{AH}$, et al. Frequency of methicillin resistant staphylococcus aureus (MRSA) colonization amongst hospital staff in teaching hospitals of Peshawar. J Med Sci. 2016; 24(4): 194-8.

21. Kobayashi T, Nakaminami H, Ohtani H, Yamada K, Nasu Y, Takadama S, et al. An outbreak of severe infectious diseases caused by methicillin-resistant Staphylococcus aureus USA300 clone among hospitalized patients and nursing staff in a tertiary care university hospital. J Infect Chemother. 2020; 26(1): 76-81. Doi: 10.1016/j.jiac.2019.07.009

22. Klevens RM, Morrison MA, Nadle J, Petit S, Gershman K, Ray $S$, et al. Invasive methicillinresistant Staphylococcus aureus infections in the United States. JAMA. 2007; 298(15): 1763-71. Doi: 10.1001/jama.298.15.1763
23. Garoy EY, Gebreab YB, Achila OO, Tekeste DG, Kesete R, Ghirmay R, et al. Methicillin-Resistant Staphylococcus aureus (MRSA): Prevalence and Antimicrobial Sensitivity Pattern among PatientsA Multicenter Study in Asmara, Eritrea. Can J Infect Dis Med Microbiol. 2019; 2019: 1-9. Doi: 10.1155/2019/8321834

24. Rozgonyi F, Kocsis E, Kristóf K, Nagy K. Is MRSA more virulent than MSSA? Clin Microbiol Infect. 2007; 13(9): 843-5. Doi: 10.1111/j.1469-0691. 2007.01780.x

25. Mizobuchi S, Minami J, Jin F, Matsushita O, Okabe A. Comparison of the virulence of methicillinresistant and methicillin-sensitive Staphylococcus aureus. Microbiol Immunol. 1994; 38(8): 599-605. Doi:10.1111/j.1348-0421.1994.tb01829.x 